\title{
O ENSINO DA CONTABILIDADE EM PORTUGAL NO SÉCULO XVIII: A AULA DO COMÉRCIO
}

\section{THE TEACHING OF ACCOUNTING IN PORTUGAL IN THE EIGHTEENTH CENTURY: THE "AULA DO COMÉRCIO”}

\section{LA ENSEÑANZA DE LA CONTABILIDAD EN PORTUGAL EN EL SIGLO XVIII: EL AULA DEL COMERCIO}

\section{MIGUEL MARIA CARVALHO LIRA}

Docente do Instituto Superior de Contabilidade e Administração de Coimbra. Bacharel em Contabilidade e Administração, Licenciado em Contabilidade e Auditoria, Mestre em Contabilidade e Auditoria, Doutorando em Gestão, Especialidade de Recursos Humanos miguel.lira200@gmail.com

\section{RESUMO}

A criação da Aula do Comércio, em 1759, foi de vital importância para o desenvolvimento da Contabilidade em Portugal e nos seus territórios ultramarinos, incluindo o Brasil. Assim, este trabalho tem por objectivo dar a conhecer o programa escolar dos primeiros cursos deste estabelecimento de ensino, com especial ênfase para o ensino da Contabilidade, e os diversos aspectos do seu funcionamento. Existe, igualmente, o propósito de explanar sobre a importância dessa instituição na evolução do pensamento contabilístico português. Para ser possível a sua concretização, este estudo elege, como metodologia, uma abordagem qualitativa e, como método de investigação, o bibliográfico. A principal conclusão a reter deste trabalho passa pela referência do pioneirismo dessa instituição no ensino da Contabilidade pelo método das partidas dobradas em território português, derivando daqui o elevado interesse da instituição.

Palavras-chaves: Aula do Comércio; História da Contabilidade; Partidas Dobradas; Portugal; Ensino. 


\section{ABSTRACT}

The creation of the "Aula do Comércio" (School of Commerce), in 1759, was of vital importance for the development of the Accounting in Portugal and its overseas territories, including Brazil. So, the objective of this paper it is to give a perspective of the school program of the first courses, with special emphasis on Accounting, and the diverse aspects of its functioning, without forgetting to display the interest of this institution in the evolution of the Portuguese Accounting. In order to make possible the concretion of these objectives, this study chooses as methodology a qualitative approach and as inquiry method the bibliographical one. The main conclusion to be drawn from this work is the fact of that it was in this institution that, for the first time, Accounting was taught through the method of the double entries in Portuguese territory, resulting from this fact its raised interest.

Keywords: Aula do Comércio; History of Accountancy; Double-Entry Bookkeeping System; Portugal; Teaching.

\section{RESUMEN}

La creación del Aula del Comercio, en 1759, fue de vital importancia para el desarrollo de la Contabilidad en Portugal y en sus territorios ultramarinos, incluyendo el Brasil. Así, este trabajo tiene por objetivo dar a conocer el programa escolar de los primeros cursos de este establecimiento de enseñanza, con especial énfasis para la enseñanza de la Contabilidad, y los diversos aspectos de su funcionamiento. Existe, igualmente, el propósito de explicar sobre la importancia de esta institución en la evolución del pensamiento de la contabilidad portuguesa. Para ser posible su concretización, este estudio elige como metodología un abordaje cualitativo y como método de investigación o bibliográfico. La principal conclusión a retener de este trabajo pasa por la referencia del pioneirismo de esta institución en la enseñanza de la Contabilidad por el método de las partidas dobles en territorio portugués, derivando de aquí el elevado interés de esta institución.

Palabras clave: Aula del Comercio; Historia de la Contabilidad; Partidas Dobles; Portugal; Enseñanza.

\section{INTRODUÇÃO}

Com a morte de D. João V, em 31 de Julho de 1750, o seu filho D. José I foi coroado Rei de Portugal. O cognome pelo qual ficou conhecido foi 'O Reformador' devido às inúmeras reformas que empreendeu durante o seu reinado. Neste trabalho apenas interessarão 
as alterações profundas preconizadas na Contabilidade portuguesa. Assim, e de acordo com Gomes (1999b, p. 17),

as mudanças na Contabilidade do nosso país foram significativas, quer ao nível da Contabilidade pública, quer ao nível da Contabilidade dos comerciantes. Todas as medidas legislativas tomadas pelo Marquês combinadas com o desenvolvimento dado ao comércio, à indústria e à agricultura levaram a uma evolução dos registos contabilísticos com a aplicação de uma forma mais sistemática e mais alargada da digrafia. Criaram também as condições para o desenvolvimento da literatura logismológica no nosso país.

O Marquês referido pelo autor é Sebastião José de Carvalho e Melo, também conhecido, em termos históricos, como Conde de Oeiras e, principalmente, Marquês de Pombal, cuja acção como ministro do Reino foi preponderante para o desenvolvimento registado durante o citado reinado, não só da Contabilidade como em quase todos os aspectos socioeconómicos do país.

No âmbito da Contabilidade, mais especificamente quanto ao ensino da Contabilidade em Portugal, esse período histórico ficou marcado por grandiosas e significativas reformas, concretizadas pela criação, há mais de 250 anos, da primeira escola comercial portuguesa: a Aula do Comércio. Contudo, deve-se recuar um pouco para que seja perceptível a necessidade dessa instituição de ensino. Assim, em Portugal, e antes da criação da Aula do Comércio, em 1759, eram parcos os conhecimentos que os comerciantes de origem portuguesa, e sem sócios estrangeiros, tinham das técnicas contabilísticas e comerciais já utilizadas quotidianamente por outros mercadores europeus. Na visão do Marquês de Pombal, essa falta de conhecimentos era a principal razão do atraso do país, impedindo o o seu desenvolvimento económico. Por isso mesmo, um dos objectivos principais da criação dessa escola foi a reversão desta deplorável e insustentável situação.

Agora uma questão se levanta: a sua importância é tal que se justifique um estudo dedicado a esta instituição? A resposta é claramente positiva, porque teve um papel crucial na evolução do pensamento contabilístico português, devido, principalmente, ao pioneirismo do seu programa escolar, até então inédito neste país. Nela foram ministradas disciplinas como Aritmética, Pesos, Medidas, Câmbios, Fretamento, Seguro Marítimo e, por fim, Contabilidade. Aqui talvez seja de referir 'Escrituração Mercantil' em vez da terminologia usada, pois, segundo Gonçalves e Marques (2010), a denominação 'Contabilidade' assumiu no século XVIII a designação de 'Escrituração Mercantil', particularmente quando associada a questões relacionadas com o ensino da disciplina.

Nessa perspectiva e com o propósito de demonstrar a importância dessa escola na expansão da Contabilidade em Portugal, os objectivos a atingir por este trabalho são dois. 
Em primeiro lugar, aludir à organização, às regras, à avaliação, entres outros aspectos relacionados com o funcionamento da Aula do Comércio. Igualmente, haverá indagação sobre a forma de leccionação das diversas matérias anteriormente referenciadas, especialmente quanto à Escrituração Mercantil, recorrendo para tal à análise do manuscrito Arte da Escritura dobrada, para Instrucçaõ de Joze Feliz Venâncio ${ }^{1}$, estudo este que permitirá retirar diversas ilações, como, por exemplo, quais as matérias contabilísticas que eram apresentadas aos alunos; que aspectos eram considerados essenciais no seu ensino, entre outros factos relevantes.

Dessa forma, este estudo é extremamente premente para um melhor entendimento da história contabilística portuguesa e dos territórios ultramarinos controlados pela Coroa portuguesa à época, incluindo o Brasil, já que os cursos leccionados até finais do século XVIII contavam com a participação de diversos alunos oriundos desse território.

Com vista à concretização dos objectivos acima enunciados, o presente trabalho apresenta cinco secções adicionais, para além desta introdução. Após a exposição da justificativa da realização de estudos em história da Contabilidade - e da Aula do Comércio em particular - e da metodologia adoptada neste trabalho, será apresentada na Secção 4 uma dissertação sobre as motivações e objectivos da criação desse estabelecimento de ensino, para além de nela serem apresentados os principais aspectos do seu funcionamento, terminando este ponto com a dissecação do programa escolar seguido. Antes da apresentação das principais conclusões, na Secção 5 o tema tratado é sobre a importância da instituição em estudo para o desenvolvimento da Contabilidade em Portugal.

\section{JUSTIFICATIVA}

O presente estudo debruça-se sobre a História da Contabilidade em Portugal. Perante este facto, muitos poderão questionar-se: será cientificamente relevante a elaboração de um trabalho nesta área de estudo? Quando se fala desta matéria, a noção que geralmente fica é a de aquisição de conhecimento supérfluo meramente ilustrativo e que servirá - apenas e exclusivamente - para enriquecer a bagagem cultural de quem tiver contacto com ele. Oculta fica, portanto, a enorme importância de um trabalho desenvolvido nessa esfera de interesse.

Para poder demonstrar essa face oculta e assim dar uma resposta positiva a esta questão pertinente, pede-se a permissao de invocar as sábias palavras de um dos investigadores mais credenciados e consagrados: "Todos sabem que o desconhecimento do passado dificulta a compreensão do presente e a prospecção do futuro. E ninguém põe em dúvida a importância que os estudos históricos assumem em todas as disciplinas técnicas ou científicas" (SILVA, 1984, p. 504). Essas duas frases, simples e directas, condensam perfeitamente a relevância que tem qualquer estudo histórico em qualquer disciplina cien- 
tífica, pelo que fica irrepreensivelmente respondida uma parte da questão e, sobre este aspecto, dissipada qualquer dúvida. E quem pronunciou tais palavras foi, tão só, um dos maiores Professores e Mestres da Contabilidade Portuguesa: Gonçalves da Silva.

No que se refere à História da Contabilidade propriamente dita, Belkaoui (1994) indica que esta é importante tanto para a pedagogia, como para a prática e política contabilística. No que respeita à pedagogia, a evolução do pensamento contabilístico pode ser uma ajuda para uma melhor compreensão e apreciação do campo da Contabilidade e da sua evolução como Ciência Social. Na perspectiva da política, o conhecimento histórico é um instrumento para uma melhor compreensão dos problemas da Contabilidade e seus contextos institucionais. Finalmente, para a prática contabilística, a História da Contabilidade pode fornecer uma melhor avaliação das práticas existentes, através da sua comparação com os métodos utilizados no passado. Curiosamente, termina o autor a sua exposição com um pedido: que se realizem, devido à importância de que se reveste esta área do conhecimento, mais investigações como a que é empreendida. Opinião similar é apresentada por Carnegie (2005, p. 16-17):

[...] uma compreensão do passado da Contabilidade pode contribuir para melhorar a nossa compreensão da natureza, papel, usos e impactos da Contabilidade de hoje e contribuir com informação que ajude no processo de tomada de decisões respeitantes aos desenvolvimentos contabilísticos de amanhã.

Para a resposta ficar completa, só falta indagar sobre a História da Contabilidade em Portugal. Será que existem trabalhos em número suficiente, tornando, assim, inútil esta nossa investigação? Não parece, se puder atender a Caiado (1999, pg. 1):

A História da Contabilidade em Portugal está praticamente por fazer. As publicações não abundam e os artigos divulgados nas revistas da especialidade também são em número reduzido [...]. Detectam-se dificuldades na escolha dos temas de investigação. As dissertações conducentes ao grau de Mestre, promovidas pelas Universidades, começam a denotar falta de criatividade. Porque não eleger as matérias da História da Contabilidade?.

Não obstante na última década terem surgido diversos autores a versar essas matérias, resultando em um aumento considerável dos estudos apresentados à comunidade científica, os trabalhos nesta temática continuam a ser completamente válidos e relevantes, pois não se pode negar que Portugal é dotado de uma cativante e extensa história, fruto do facto de ser uma das mais antigas nações do mundo e de ter desempenhado um importante papel na história mundial, designadamente aquando da expansão portugue- 
sa, vulgarmente conhecida como "Os Descobrimentos". Assim, de acordo com Carnegie (2005), Portugal proporciona a qualquer investigador uma grande diversidade de eventos e assuntos a explorar e que permitirão aprofundar o conhecimento e a compreensão do passado, englobando, nessa perspectiva, a Contabilidade, pois esta é, obviamente, uma componente essencial da história de qualquer nação e/ou região, representando os registos contabilísticos descrições sociais importantes da acção humana.

E quanto a estudos cujo tema seja a Aula do Comércio, propriamente dita? Sem dúvida nenhuma, que devem existir pois esta instituição de ensino constitui um autêntico marco na história da Contabilidade portuguesa, derivado do facto de ter sido a primeira escola mercantil portuguesa, de carácter público e técnico-profissional, sendo igualmente pioneira na leccionação da Contabilidade, ou Escrituração Mercantil, por partidas dobradas, também conhecido como método italiano.

\section{METODOLOGIA}

Nesta secção, será abordada a questão da metodologia utilizada neste trabalho. Antes de mais, pode-se começar por indicar que a metodologia da pesquisa consiste no método e nas técnicas que o investigador utiliza para realizar a pesquisa, enquanto que a pesquisa não é mais do que o conjunto de investigações, operações e trabalhos, quer seja a um nível intelectual ou prático, cujo objectivo seja a descoberta de novos conhecimentos, a invenção de novas técnicas e a exploração ou a criação de novas realidades (KOURGANOFF, 1990).

O protocolo utilizado na pesquisa respeitou os seguintes trâmites, de acordo com a concepção de Raupp e Beuren (2006):

- quanto aos objectivos: descritiva;

- quanto aos procedimentos: bibliográfica;

- quanto à abordagem do problema: qualitativa.

Para Raupp e Beuren (2006), a pesquisa descritiva configura-se como um estudo intermediário entre a pesquisa exploratória e a explicativa, isto é, não se apresenta tão preliminar como a primeira nem tão aprofundada como a última. Ainda segundo estes autores, as pesquisas bibliográficas são desenvolvidas mediante material já trabalhado, ou seja, fontes de evidência secundárias, principalmente livros e artigos científicos (e técnicos e/ou académicos). Neste aspecto, pode-se também considerar a opinião de Cervo e Bervian (2002), que indicam que a pesquisa bibliográfica explica um problema a partir de referenciais teóricos publicados em documentos e que pode ser realizada independentemente ou como parte da pesquisa descritiva ou experimental. Por seu lado, a investigação 
qualitativa é aquela que não utiliza instrumento matemático, estatístico ou econométrico algum (RAUPP; BEUREN, 2006), requisitos que são na prática preenchidos pelo presente estudo, possibilitando assim a sua classificação como uma pesquisa com uma abordagem metodológica qualitativa.

Em resumo, pode-se considerar que o actual trabalho visa concorrer para o incremento do conhecimento da história da Contabilidade portuguesa, no seu geral, e para a divulgação da importância da Aula do Comércio na evolução do pensamento contabilístico português, em particular, sendo este baseado em pressupostos teóricos interpretativos, adoptando como metodologia uma abordagem qualitativa e como método de investigação o bibliográfico.

\section{AULA DO COMÉRCIO}

\subsection{Breve contextualização histórica}

Quando D. João V faleceu, em 1750, e não obstante o seu reinado ter imprimido grande notoriedade ao cultivo das letras, à magnificência das construções e ao incremento das artes e da fabulosa riqueza em ouro, diamantes e pedras preciosas que provinham do outro lado do Atlântico, do riquíssimo território brasileiro, o país estava em uma gravíssima situação económica e financeira, despovoado, sem desenvolvimento agrícola, sem estradas ou transportes (GONÇALVES, 2010, p. 164). Para além disso, existiam diversos problemas que urgia resolver: uma máquina administrativa totalmente inoperante; fraudes, usos e especulações de todas a espécie nas organizações dependentes do Estado; a estagnação da indústria em Portugal; e a decadência do comércio que, na sua maioria, estava em poder de mercadores estrangeiros (GOMES, 1999a, p. 550).

Dessa forma, D. José - que sucedeu no trono a D. João $V$ - logo tomou a decisão de criar um gabinete ministerial com indivíduos que lhe parecessem capazes de reagir a esta situação nefasta e que conseguissem tomar providências severas capazes de erguerem as novas estruturas administrativas necessárias para que o País pudesse sair do caos financeiro e administrativo que se instalara, e não comprometido com o estilo de governação anterior, assente em três Secretarias de Estado: Marinha e Ultramar; Negócios Interiores do Reino; e Negócios Estrangeiros e Guerra, sendo que esta última pasta foi destinada a Sebastião José de Carvalho e Melo (GONÇALVES, 2010, p. 164). Gradualmente, o Marquês de Pombal foi concentrando em si os poderes dos outros Secretários, tornando-se, nos parâmetros ocidentais actuais, um ditador (CARVALHO, 1996, p. 424).

A importância dessa figura na história portuguesa do século XVIII é inquestionável, mas salienta-se aqui a tentativa de modernização da indústria e do comércio e a drástica reforma do sistema educacional. Deveras importante, para não dizer fundamental na perspectiva deste trabalho, é também a sua activa participação na evolução da Contabilidade. A 
sua ditadura foi uma época áurea e determinante na evolução do pensamento contabilístico em Portugal, relevando-se como significativo o progresso conseguido com a introdução em uma Instituição Pública - o Erário Régio - da partida dobrada à italiana ou através da criação da Aula do Comércio.

A sua clarividência fez-lhe compreender, na linha da escola mercantilista, que o progresso da nação passaria, obrigatoriamente, não só pelo fomento e pela modernização do comércio, como também pela transmissão do conhecimento por via institucional (ESTEVENS, 2000, p. 7). A influência mercantilista também é defendida por Rodrigues, Gomes e Craig (2010, p. 39):

Em Londres, o Marquês de Pombal tinha ficado impressionado com as políticas mercantilistas que observou enquanto enviado especial do Rei D. João V na corte inglesa do Rei George II, durante o período1738-1743. Durante esse período ficou claro para o Marquês de Pombal que para imitar o sucesso do mercantilismo britânico, para desenvolver o comércio e a actividade económica em Portugal, e para melhorar e expandir a classe dos mercadores, seria necessário criar a Aula de Comércio.

Assim, a implementação da Aula de Comércio inseriu-se em um conjunto de medidas destinadas a tornar o país independente e forte e que se podiam sintetizar em dois aspectos: criação de indústrias que, à época, eram em número diminuto; e aumentar os conhecimentos das técnicas comerciais dos comerciantes e industriais (GOMES, 2000, p. 141), tendo por inspiração o espírito do lluminismo da época. Este assentava na premissa de que a razão humana era a forma de combater a ignorância, a superstição e era a base para a construção de um mundo melhor, apoiando-se, para tal, no mercantilismo e nos mercadores (RODRIGUES; GOMES; CRAIG, 2007).

\subsection{Criação da Aula do Comércio}

É pelo Alvará de aprovação dos Estatutos da Aula do Comércio, de 19 de Maio de 1759, e registado em 22 de Maio do mesmo ano na Secretaria de Estado dos Negócios do Reino, no Livro 2 da Junta do Comércio (GUIMARÃES, 2010, p. 32), que se dá início ao ensino, a um nível oficial e público, da Contabilidade por partidas dobradas em Portugal, pois nesse mesmo ano, a 1 de Setembro, iniciou-se o primeiro curso, com a duração de três anos ${ }^{2}$.

É de sublinhar que os seus estatutos foram publicados em execução do capítulo XVI do Decreto de 30 de Setembro de 1755, que criara a Junta do Comércio ${ }^{3}$, tornando esta uma escola estatal e laica, financiada pela referenciada Junta, sendo por isso sintoma e agente do reforço do poder do Estado, preconizado pelo Marquês de Pombal. Coube a esta 
Junta a responsabilidade da criação da Aula do Comércio, tendo nesse contexto apresentado os estatutos da Aula em 10 de Abril de 1759, que continham 19 parágrafos, posteriormente confirmados por Alvará de 19 de Maio do mesmo ano. Para além da apresentação dos estatutos, a Junta superintendeu a Aula e efectuou diversas diligências tendentes a dar execução aos objectivos previamente delineados, como, por exemplo: a aquisição de instalações; a selecção dos professores; a elaboração de normas regulamentares; o exercício de uma acção de fiscalização, etc.

Tornou-se, como salienta Sousa (1985, p. 546), no primeiro estabelecimento de ensino técnico-profissional de Portugal a versar as matérias comerciais e contabilísticas e onde se deveriam formar os futuros quadros da administração pública e das empresas da época. Mas, acima de tudo, destacou-se pela sua importante contribuição para um melhor emprego da partida dobrada em Portugal.

Neste ponto terá todo o interesse colocar-se a questão: quais terão sido os vectores culturais, políticos, económicos que levaram ao aparecimento da nova escola? Segundo Santana ${ }^{4}$, citado por Rodrigues, Gomes e Craig (2003a, p. 47):

1. Há a considerar que as notáveis reformas e iniciativas no domínio do ensino levadas a cabo em Portugal na segunda metade do século XVIII resultaram da convicção existente no país de que as condições práticas do ensino eram muito fracas e que se tornava necessário melhorá-las.

2. Por outro lado, houve durante a primeira metade do século um grande movimento de interesse pelos problemas no ensino que se traduziu em importantes obras, algumas delas na área do Comércio.

3. Acresce ainda o encerramento das escolas dos Jesuítas e o conhecido ódio do Marquês de Pombal em relação a estes, que o terão levado à criação do ensino comercial à margem da influência jesuítica, já que eram estes ofereciam grande parte da educação em Portugal antes de 1759.

4. Mas é nos condicionalismos económicos (ligados à ascensão burguesa) e na remodelação administrativa (tão importante para a consolidação do Estado Absoluto seguido pelo Marquês de Pombal) que se encontram as principais razões para a criação de uma escola destinada a preparar negociantes instruídos, guarda-livros eficazes e funcionários competentes. De facto, a criação do organismo executante da política pombalina e coordenador das actividades económicas do País - a Junta de Comércio - acabou por trazer ao de cima a falta de ordem que causava a ruína dos seus proprietários. Esta situação, aliada ao facto de os funcionários do Estado estarem mal preparados, exigia medidas urgentes e, por isso, o Marquês de Pombal criou a Aula do Comércio. 


\subsection{Aspectos gerais do funcionamento da Aula do Comércio}

Para ser admitido na Aula do Comércio, era necessário ser português e ter 14 anos completos (idade mínima de ingresso). Outros pré-requisitos, de acordo com os Estatutos, eram: saber escrever; ser hábil nas quatro operações; existindo a preferência por filhos ou netos de homens de negócios. De acrescentar que a frequência das aulas era limitada a vinte assistentes ou alunos, podendo alargar-se a mais trinta, no máximo, considerados como supranumerários, visto que não era conveniente que um só Lente tivesse mais de 50 alunos (GONÇALVES, 2010, pp. 165-166).

No que concerne à avaliação dos aulistas, esta era composta por duas componentes: avaliação final formalizada através de exames públicos ${ }^{5}$; e uma espécie de avaliação contínua ao longo do ano lectivo através de chamadas orais aos Sábados, chamadas Exercícios Sabatinais, e que foram descritas, com detalhe, por Rodrigues, Gomes e Craig (2003a, p. 49): o Lente sorteava aleatoriamente na véspera, ou mesmo no próprio dia, seis discípulos, em que três eram arguentes e três defendentes e que, em forma de argumento, explicavam as matérias leccionadas durante a semana. Cabia ao Lente presidir a esta discussão e esclarecer qualquer dúvida que surgisse. Para além dos Exercícios Sabatinais, existiram as Decúrias ${ }^{6}$. Assim, na parte da tarde dos dias da semana, eram nomeados pelo Lente dois discípulos que ensinavam e explicavam aos seus colegas as lições tratadas nas aulas propriamente ditas, que se realizavam de manhã. Esta iniciativa tinha por objectivo não só melhorar a compreensão das matérias, como também apoiar a sua memorização. Poderiam servir, igualmente, como referência ao Lente aquando da elaboração do seu parecer para a admissão, ou não, dos alunos ao exame final. Em termos de classificação, esta não era dada em termos numéricos, já que os alunos eram agregados em dois escalões: aprovados; e reprovados. Dentro do primeiro, existiam subescalões: Suficiente, Bom, Muito Bom e Óptimo (existiram poucos ao longo da existência da Aula).

Retornando à questão das aulas, e segundo Caiado (2000, p. 3), estas tinham lugar todas as manhãs, com horário diferenciado no Inverno e no Verão: no Inverno $8 \mathrm{~h}$ - 12h; no Verão $7 \mathrm{~h}-11 \mathrm{~h}^{7}$. As aulas tinham, dessa forma, a duração de quatro horas, contínuas, utilizando o Lente a segunda metade para exposição de matéria nova, após ter questionado os aulistas sobre a matéria do dia anterior. Contudo, além das aulas, os alunos teriam de frequentar as Decúrias, como referido anteriormente.

Para tornar mais apelativo o ingresso na Aula do Comércio, foram dadas algumas preciosas regalias aos aulistas. Por exemplo, a Carta de Lei de 30 de Agosto de 1770 impõe restrições ao acesso a determinados cargos públicos, obrigando esta legislação a contratar pessoas formadas pela Aula do Comércio $^{8}$, para além de estabelecer os ordenados para os Guarda-Livros diplomados, entre outras medidas tomadas pelo Marquês de Pombal (GONÇALVES, 2010, p. 166). 
Uma última questão a abordar neste ponto é a da escolha dos Lentes. Esta foi sempre muito cuidadosa, na medida em que este cargo era considerado de enorme importância e prestígio. Contudo, de início, foi difícil encontrar professores versados nas matérias que eram explanadas na Aula do Comércio pois à época, e como já foi referido, existiam poucos conhecimentos dessas matérias entre os cidadãos nacionais ${ }^{9}$ (RODRIGUES; CRAIG, 2004).

Não obstante estas limitações e restrições, e ainda segundo Rodrigues e Craig (2009), conseguiu-se encontrar o primeiro Lente da Aula do Comércio na pessoa de João Henrique de Souza. Este era de nacionalidade portuguesa, sendo reconhecido na época por ser muito hábil na profissão de contabilista. Nasceu em 1720, foi educado por um cidadão de nacionalidade francesa, Miguel Lebouteux, entre os 7 e 12 anos, e com ele aprendeu francês. Foi com esta idade que iniciou a sua vida profissional nos escritórios de comerciantes italianos, onde permaneceu vários anos antes de se aventurar fora de Portugal Continental passando por cidades como Buenos Aires ou Rio de Janeiro, retornando a Lisboa em 1755. De acrescentar que foi igualmente o idealizador dos estatutos da Aula do Comércio e da organização do Erário Régio (MARTINS, 1952, p. 446).

Aquando da sua nomeação como escrivão do Erário Régio, em 11 de Janeiro de 1762, deu-se a sua substituição na Aula por Alberto Jacqueri de Sales. Este Lente iniciou o segundo curso em 1 de Julho de 1763, que teve o seu terminus no Natal de 1767. Martins (1960, p. 81), sobre este Professor escreve: "era suíço, mas naturalizado português, calvinista, mas convertido à religião católica, auferindo pelo exercício de Lente da Aula 3.000 cruzados, tendo-Ihe ainda sido concedido o Hábito de Cristo. Era especialista em Matemática e Ciências Comerciais".

Em 1767, dado o grande aumento do número de aulistas, a Junta do Comércio propõe a nomeação de mais um docente, Inácio da Silva Matos e após a demissão de Sales, pela Junta do Comércio em 1784, por supostas irregularidades e incapacidade como docente, (RODRIGUES; CRAIG, 2009), foi substituído por José Honório Guerner, um antigo aulista, que garantiu o funcionamento da Aula durante um curto período de tempo. A partir de então, e à medida que o curso se desenvolvia, o recrutamento de docentes era feito junto de antigos alunos.

\subsection{Programa escolar dos primeiros cursos e o ensino do método das partidas dobradas}

De acordo com Martins (1952, p. 439), embora não existisse nos estatutos da Aula do Comércio um grande aprofundamento do teor dos programas das matérias a leccionar, podem-se retirar desses que existiriam dois grandes núcleos de ensino, em que eram englobadas as diversas matérias: a Aritmética e a Contabilidade Comercial. No núcleo da Aritmética, incluíam-se, para além da Aritmética e da Geometria, o estudo de Pesos e Medidas, Fretes, Seguros e Câmbio. Sobre o núcleo da Contabilidade é referido que "se ensinassem 


\section{repec}

os principios necessarios a qualquer Negoceante perfeito, e pela communicação do methodo Italiano, aceite em toda a Europa".

Existia uma ordem pela qual deveriam ser leccionadas as diversas matérias, existindo mesmo uma ressalva nos próprios Estatutos da Aula do Comércio que indicava que se devia procurar sempre "que não passe de humas a outras materias, e ainda dentro dellas, de humas a outras partes, sem que em todos haja hum geral conhecimento do que já for dictado". A primeira disciplina a leccionar seria a Aritmética, visto ser o princípio de todo e qualquer comércio, e incluía o ensino das quatro operações aritméticas passando, posteriormente, para matérias mais complicadas como a regra de três ou o estudo dos números fraccionários.

Ao ensino da Aritmética seguia-se o estudo dos Pesos, Medidas e Câmbios de diversas praças de comércio, especialmente aquelas com que Portugal habitualmente mantinha relações comerciais. Gonçalves $(2010$, p. 166) realça que "era de grande complicação o estudo de pesos e medidas, não apenas de país para país, mas dentro do próprio território nacional, no qual, não havendo padrões de normalização, mesmo nas províncias portuguesas se aplicavam modelos díspares”.

É de salientar a importância dada aos câmbios nos Estatutos: "será esta importante materia huma parte do principal cuidado do ensino das Assistentes da Aula”. Não obstante a percepção da sua utilidade e do largo tempo despendido com esta, era manifesto que apenas seriam ensinadas as primeiras e suficientes disposições que seriam posteriormente consolidadas com a prática profissional.

A próxima matéria a abordar era a dos Seguros (eram estudados as apólices e as suas formalidades), seguida dos Fretes (as suas formalidades, comissões e obrigações) tanto das praças portuguesas como estrangeiras. A esse respeito, Rodrigues, Gomes e Craig (2003a, p. 50) indicam que "seria também importante o conhecimento de sólidos, para por meio das suas dimensões se saber o volume necessário para regular os fretes que são transportados para o Brasil".

Os mesmos autores referem, igualmente, que as últimas aulas eram reservadas para explicar aos alunos a Contabilidade por partidas dobradas, distinguindo-se, para o efeito, o comércio por grosso da venda a retalho. A contabilidade por partida dobrada leccionada na Aula tinha como base os livros contabilísticos Borrador, Diário, Razão e Auxiliares, sem esquecer o estudo dos Balanços e a exemplificação de como se trabalhava em partida dobrada.

Tal pode ser comprovado através do manuscrito "Arte da Escritura dobrada, para Instrucçaõ de Joze Feliz Venâncio", o qual foi igualmente assente nas aulas de Henrique de Sou$\mathrm{za}^{10}$, primeiro Lente desta escola. Deste documento podem-se retirar diversas ilações sobre o ensino da Contabilidade pelo método italiano em Portugal, em pleno século XVIII ${ }^{11}$. 
Figura 1 - Capa do manuscrito Arte da Escritura dobrada, para Instrucçaõ de Joze Feliz Venâncio

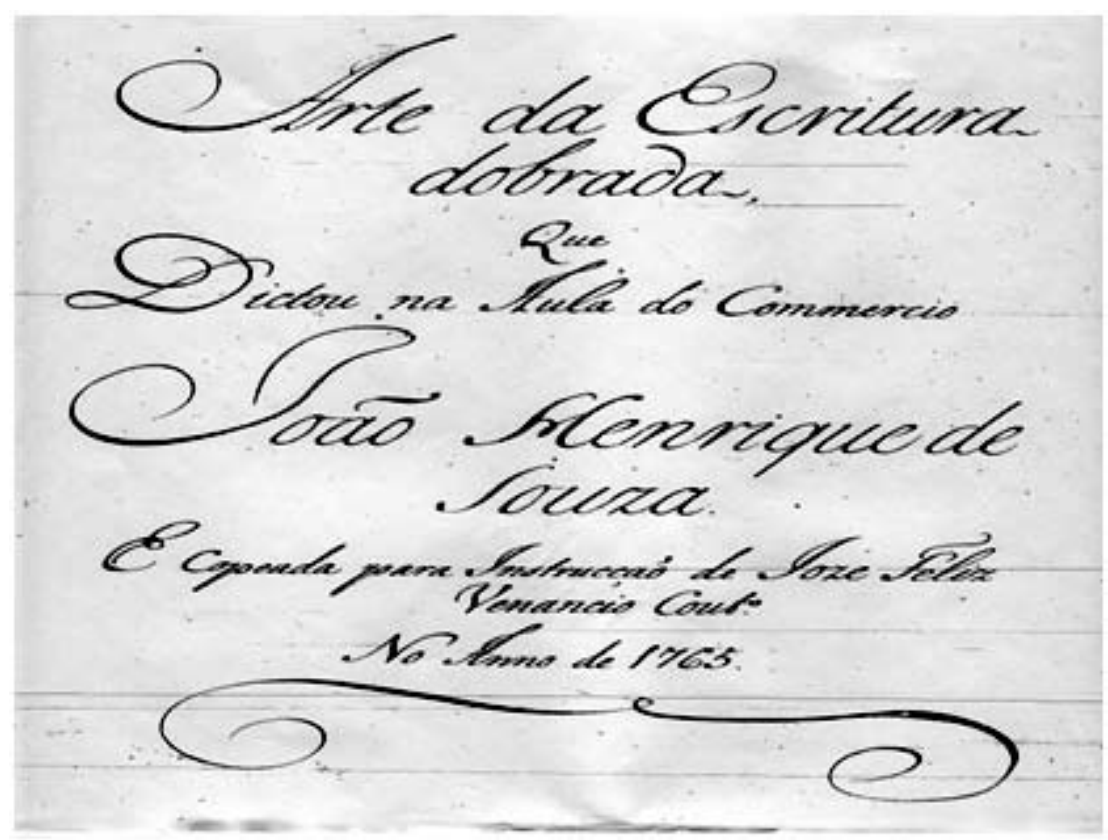

Fonte: Souza (1765).

O manuscrito inicia-se com uma pequena introdução de três páginas, onde é vincada a importância do método da partida dobrada ou Scritura doppia, sendo referido que este método é o praticado pela maioria dos negociantes da Europa. Apresenta, igualmente, e de uma forma sumária, os livros a utilizar e as ideias base de funcionamento do método. Nessa perspectiva, indica que na escritura dobrada são usados os seguintes livros gerais, e pela ordem aqui apresentada: Borrador, Diário e o Razão. Esta convenção está de acordo com o apresentado por Luca Pacioli, no seu Tractactus de computis et scripturis, integrado na sua obra denominada Summa de Arithmetica, Geometria Proportioni et Proportionalita, publicada em Veneza em 10 de Novembro de 1494, onde o método italiano foi exposto pela primeira vez em forma de obra impressa. Pacioli, segundo Oliveira (2009, p. 366), identifica a necessidade de utilização de três livros principais: Memorial (ou Livro de Rascunho, que corresponde ao Borrador aqui apresentado), Diário e Razão (ou Livro Maior). Para além destes, os aulistas também aprendiam que deviam ser utilizados os Livros Auxiliares, em número incerto, já que este decorria da quantidade ou natureza dos negócios ${ }^{12}$.

Esta primeira abordagem servia, então, para realçar a importância do método das partidas dobradas, seguida da apresentação, análise e principais regras a observar na escrituração dos três livros contabilísticos a utilizar: Borrador, Diário e Razão. Não deverá ser desprezado o facto de estas bases teóricas serem complementadas com vários exemplos 


\section{repc}

práticos. Por exemplo, aquando do estudo do Diário são apresentados vários exemplos, dos quais são reproduzidos dois:

15 de Maio de 1760

FAZENDAS GERAIS DEVEM

A PEDRO TOIMPSON

DEVEM $80 \$ 625$

Por um metro de pano fino com $37 \%$

$80 \$ 625$

3 de Agosto de 1760

HOFFSAN E DECHAMBERGH DEVE

A CAIXA

Que the paguei pelo que the devia

$58 \$ 000$

Quanto ao formato das contas do Razão, será de todo o interesse apresentar dois exemplos retirados do manuscrito em estudo, o que permitirá ficar com uma percepção mais clara do aspecto de um Razão do século XVIII, conforme era ensinado na Aula do Comércio (ver figura 2).

Figura 2 - Dois exemplos de folha do livro de Razão, retirados do manuscrito Arte da Escritura dobrada, para Instrucçaõ de Joze Feliz Venâncio

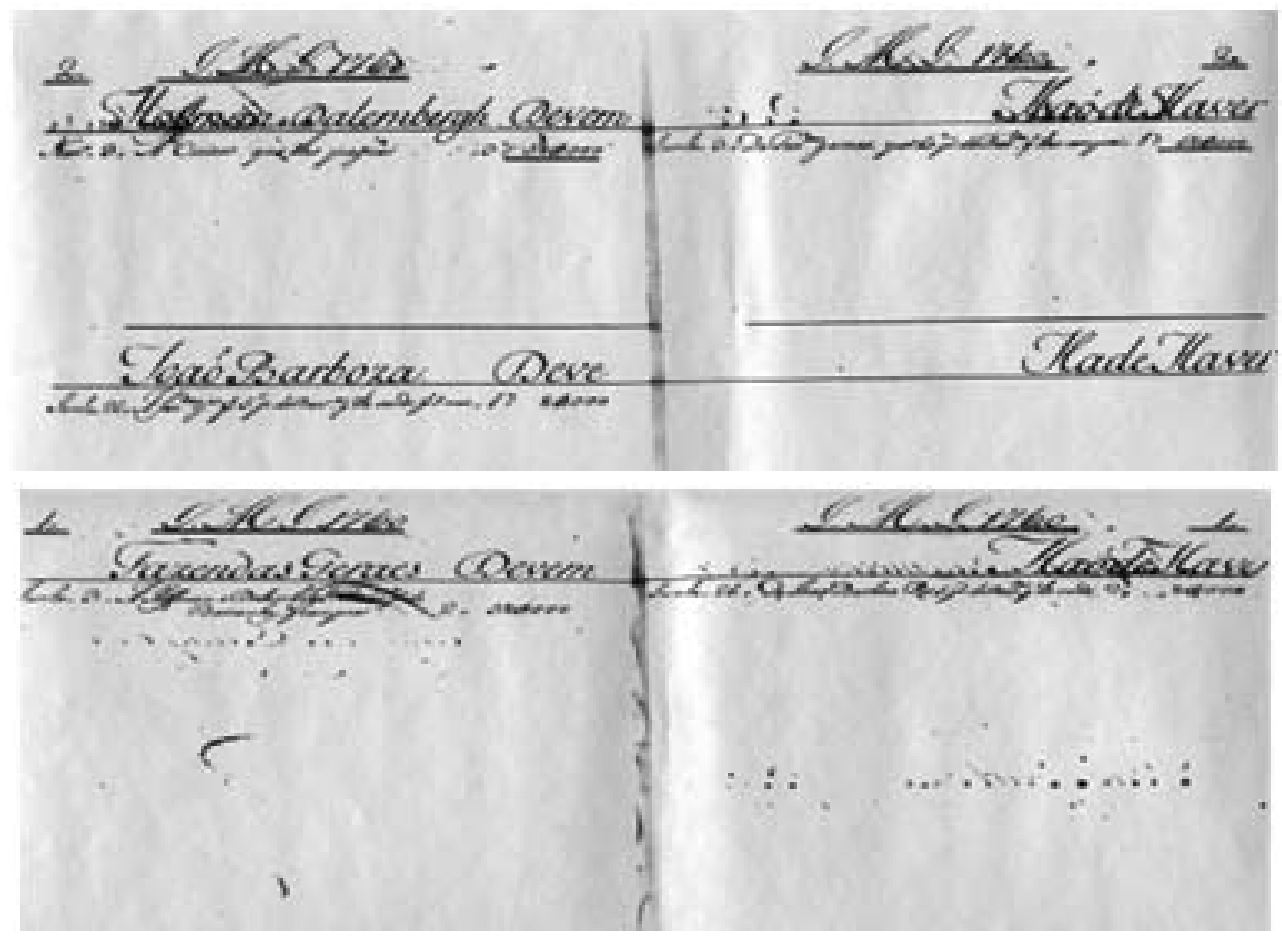

Fonte: Souza (1765). 
A ordem pela qual estes eram estudados correspondia à ordem que deviam ser escriturados, isto é, em primeiro lugar as operações eram registadas, com pormenor e de uma forma pouco formal, no Borrador. As informações aí recolhidas permitiam, mais tarde, a contabilização no Diário, e que de forma sistemática eram transportadas para as contas do Razão. Deve ser realçado que os princípios fundamentais do método italiano eram apresentados ao mesmo tempo que era exposto e estudado o primeiro livro que o utilizava: o Diário.

Após o estudo dos livros contabilísticos a utilizar, passava-se para outro aspecto fundamental da Contabilidade: a elaboração dos Balanços (que seriam de três tipos): Caixa; do Razão; e de saída para outro livro de Razão. O mais importante seria o Balanço do Livro de Razão, ou Balanço Geral, que se devia realizar no final de cada ano e que era uma prova infalível da correcção das contas, já que a soma dos saldos das contas a débito tinha de ser igual à soma dos saldos das contas a crédito ${ }^{13}$.

Figura 3 - Exemplo de um Balanço do Livro de Razão contido no manuscrito Arte da Escritura dobrada, para Instrucçaõ de Joze Feliz Venâncio:

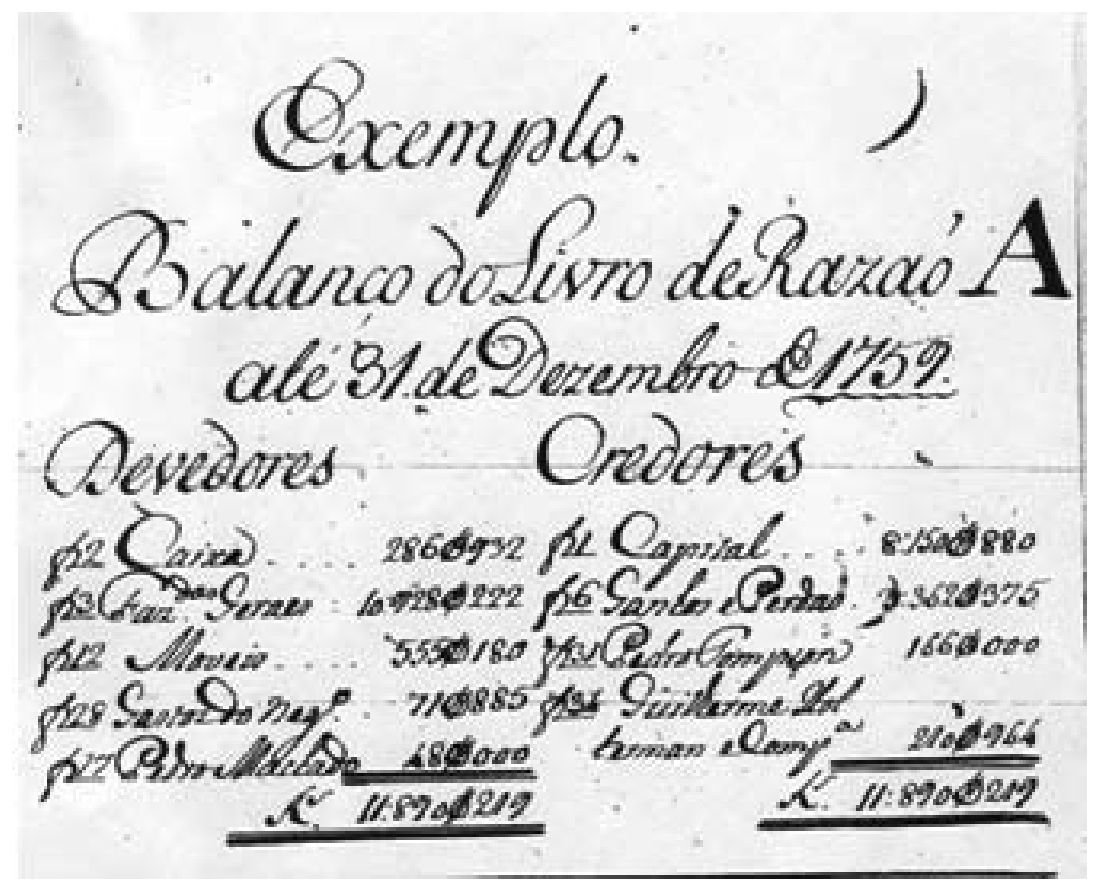

Fonte: (Souza, 1765).

Através do exemplo da Figura 3, podem-se tirar algumas ilações deveras pertinentes. A primeira é que as indicações da página antes do nome das contas ali presentes referemse às páginas do Razão, onde elas se encontram. Por exemplo, neste exemplo a conta de Caixa está na página 2 do Razão; a conta de Capital está na primeira página do Razão, etc. A segunda dedução que pode ser inferida é que a ordem das contas não condiz com a 
actualmente utilizada, sem falar que o Balanço aqui apresentado é de cariz horizontal, ao contrário da posição vertical proposta pelo novo Sistema de Normalização Contabilística português. Já agora, e como seria expectável, este Balanço não era tão completo como os actuais, deixando de fora a questão dos Activos Fixos Tangíveis e das suas depreciações. Por fim, não estão presentes explicitamente os conceitos de Activo e Passivo, como hoje os são entendidos.

Outra conclusão que se pode retirar é a de que muitas das regras apresentadas e dos cuidados a ter na escrituração e elaboração do Balanço do Razão ainda hoje fazem sentido e são válidas. Podem-se aqui citar alguns exemplos:

- A necessidade de confirmar as dívidas de e a terceiros, através do envio, atempadamente, de cópia das contas aos interessados, de forma a permitir a elaboração de um Balanço do Razão que mostrasse uma imagem verdadeira e apropriada das contas.

- As entradas, pelos sócios, em géneros são escrituradas pelo justo valor dos bens, sendo que este é obtido através de uma avaliação prudente.

- Nas contas onde eram contabilizados alguns tipos de bens ("Bens Móveis" e "Bens de Raiz"), hoje considerados como activos fixos tangíveis, era realizado, ciclicamente, o apuramento do seu justo valor. A diferença entre este e a escriturada era levada à conta de "Ganhos e Perdas", entre outras.

Obviamente que existem diferenças em diversos aspectos, não seria de esperar outra coisa. Um exemplo é a não separação, em termos contabilísticos, entre o património particular e o património comercial do(s) proprietário(s) de determinada empresa, como se pode facilmente constatar pela explicação dada para a movimentação da conta geral do Razão intitulada "Capital".

É igualmente dedicado um capítulo à análise do Balanço, intitulado "Reflexoens que naturalmente deve fazer o Mercador de Logea de Capella depois de tirar o Balanço", que corresponde a uma análise dos valores do Balanço e quais as conclusões a retirar destes.

Da análise deste manuscrito, pode-se, igualmente, deduzir que, tal como hoje, o ensino da Contabilidade na Aula do Comércio partia das suas bases gerais para depois evoluir para o estudo de casos mais particulares e mais complexos, mas que não deixavam de se basear nas tais regras gerais previamente assimiladas. Assim, até a página 86 o que este livro apresenta não são mais do que as regras gerais do método das partidas dobradas e dos livros contabilísticos que devem ser utilizados neste método. Nas páginas seguintes, isto é, da página 86 a 160, são objecto de estudo novas variações do método até aí exposto e o registo contabilístico de operações mais complexas e expostas no capítulo "Reflexoens sobre a Escritura Dobrada dirigidas a mayor intelligencia desta Arte", não sendo esquecida, igualmente, a questão da aplicação do método italiano a diferentes tipos de negócios, visto 
que até esse momento o método explanado estava direccionado para uma perspectiva contabilística dos negócios de um comerciante particular.

Como se pode constatar da análise do capítulo "Applicação da Escritura Dobrada aos diversos negocios q se podem oferecer", são indicadas as diferenças existentes na aplicação do método de partidas dobradas a companhias gerais, a fábricas, a casas de fidalgos e mais pessoas ricas, e as administrações de negócios alheios.

\section{A IMPORTÂNCIA DA AULA DO COMÉRCIO PARA O DESENVOLVIMENTO DA CONTABILIDADE EM PORTUGAL}

Gomes (1999b, p. 10) defende que antes da criação da Aula existia, relativamente a outras nações da Europa, um grande atraso em matéria de conhecimentos e técnicas comerciais que impedia o desenvolvimento económico do país. Acrescenta Marques (2000, p. 110) que a falta de compêndios de Contabilidade, originais ou traduzidos, foi, ao mesmo tempo, causa e efeito do atraso português nesta matéria.

Para comprovar esta situação, Boxer (1977, p. 370) afirma que, em 1755, apenas existiam três firmas portuguesas (Bandeira, Ferreira e Brito), todas sedeadas em Lisboa, que tinham livros de registo com escrita de dupla entrada, cujos directores conheciam razoavelmente as moedas, pesos e medidas estrangeiras, e os movimentos comerciais e câmbios de Londres, Amesterdão e Paris. Para além dessas três firmas portuguesas, também tinham conhecimento do método italiano diversos negociantes estrangeiros. Para além desses exemplos, Oliveira (2009) acrescenta outro: a Companhia Geral da Agricultura das Vinhas do Alto Douro, que utilizava, desde o ano da sua criação - 1756 -, o método das partidas dobradas.

Do parágrafo anterior, facilmente se depreende acerca da necessidade da existência, em Portugal, de um estabelecimento de ensino público que, de um modo organizado, sistemático e com um carácter regular, leccionasse contabilidade por partida dobrada e demais matérias necessárias à actividade comercial.

Um dos objectivos principais da criação da Aula do Comércio foi, então, a reversão desta deplorável e insustentável situação. Como forma de atingir este objectivo, foi introduzido - pela primeira vez em Portugal - o ensino da Contabilidade por partidas dobradas em um estabelecimento de ensino público, de um modo sistemático, organizado e com um carácter regular. Adiante-se que ela constitui uma revolução no ensino da segunda metade do século XVIII, na medida em que até essa altura o ensino estava apenas ligado às ordens religiosas e à Universidade. Pode-se mesmo afirmar que a Aula do Comércio foi criada no âmbito "de uma ampla agenda de reformas educacionais que foram implementadas na segunda metade do século XVIII pelo Marquês de Pombal com o objectivo de melhorar o estado geral da educação em Portugal” (RODRIGUES; GOMES; CRAIG, 2010, p. 39). 
Se é certo que só após alguns anos depois da fundação da Aula do Comércio é que passaram a existir contabilistas portugueses devidamente habilitados, a partir desse momento não foi mais necessário recorrer ao emprego exclusivo de contabilistas estrangeiros, uma vez que a oferta local se tornou disponível. Esta nova classe de contabilistas nacionais exerceu a sua actividade não só nos escritórios dos negociantes, mas também em instituições públicas (RODRIGUES; GOMES; CRAIG, 2003b, p. 102).

Pode-se concluir este ponto com uma constatação deveras importante: verifica-se que nesta escola eram leccionadas algumas das matérias que ainda hoje são básicas em qualquer curso de Contabilidade, tratando-se de um curso com grande carácter teóricoprático. Assim, e observando que todos os sectores da sociedade portuguesa foram fortemente influenciados e enriquecidos por esta ocorrência, Guimarães (2000, p. 3) admite que este acontecimento está na base do ensino das ciências empresariais em Portugal, constituindo o seu ponto de partida.

A questão do pioneirismo da Aula do Comércio foi abordada por Rodrigues, Gomes e Craig (2010). Após a sua investigação chegaram a resultados deveras animadores, pois apontam para a elevada probabilidade de a Aula do Comércio ter sido a primeira escola estatal de negócios a ser criada não só em Portugal, como também na Europa. Contudo, realçam que as investigações realizadas não passaram as fronteiras do continente europeu, sendo, por isso, de admitir que é concebível que uma escola deste tipo possa ter existido fora da Europa, antes da criação da Aula de Comércio.

\section{CONCLUSÃO}

Nesta súmula dos principais aspectos a reter do presente trabalho, pode-se começar por referir que a Aula do Comércio, criada em 1759 e superintendida pela Junta do Comércio, é fruto da influência do Marquês de Pombal e foi enquadrada na sua política de desenvolvimento do país, sendo esta a primeira escola mercantil portuguesa, de carácter técnico-profissional, cuja criação tinha por objectivo a reversão da insustentável situação que se assistia, em Portugal, em pleno século XVIII: parcos (ou inexistentes) conhecimentos comerciais e contabilísticos nas principais praças portuguesas, por parte dos comerciantes e mercadores nacionais das principais praças portuguesas.

Este facto, só por si, era suficiente para que este estabelecimento de ensino tivesse o seu lugar na História portuguesa. Mas, se se acrescentar que foi a primeira instituição a leccionar Contabilidade por partidas dobradas, passa, igualmente, a constar, e com grande destaque, na História da Contabilidade portuguesa.

De realçar que as influências mercantilistas e iluministas do Marquês de Pombal, as quais Ihe foram incutidas aquando da sua passagem pela Inglaterra, tiveram um papel preponderante, e quiçá imprescindível, para a sua intenção de conceber e desenvolver este 
estabelecimento de ensino. Ao se somar a esta questão os diversos condicionalismos económicos e sociais sentidos à época e que provocaram o atraso do país em relação aos seus congéneres europeus, fica-se, assim, perante todos os vectores cuja conjugação levou ao aparecimento desta nova escola.

A matéria leccionada nessa Aula abarcava as necessidades específicas e sentidas à época e estavam de acordo com os objectivos da sua criação. Assim, para além do núcleo de Contabilidade, existia um segundo: o da Aritmética. Contudo, neste trabalho destaca-se quase exclusivamente - o ensino da Contabilidade por partida dobrada. Para tal, recorrereuse ao manuscrito Arte da Escritura Dobrada, para Instrucçaõ de Joze Feliz Venâncio. Este foi baseado nas aulas do primeiro Lente deste estabelecimento de ensino, permitindo, dessa forma, expor o método de ensino das matérias constantes do núcleo da Contabilidade.

Da sua análise, foi retirado que as aulas tinham uma feição teórico-prática, pois as bases teóricas iniciais eram complementadas com vários exemplos práticos. A primeira abordagem do tema servia para realçar a importância do método italiano, seguida da apresentação, análise e principais regras a observar na escrituração dos três livros contabilísticos a utilizar: Borrador, Diário e Razão.

A ordem pela qual estes eram estudados correspondia à ordem que deviam ser escriturados, isto é, Borrador, Diário e finalmente o Razão. É de referir que os princípios fundamentais do método italiano eram apresentados aquando do estudo do Diário já que este era o primeiro, dos 3 livros contabilísticos previamente referidos, a utilizá-lo. Após o estudo dos livros contabilísticos a utilizar, passava-se para outro aspecto fundamental da Contabilidade: a elaboração dos Balanços (que seriam de três tipos).

Pode-se, igualmente, deduzir que, tal como hoje, o ensino da Contabilidade na Aula do Comércio partia das suas bases gerais para depois evoluir para o estudo de casos mais particulares e mais complexos, mas que não deixavam de se basear nas tais regras gerais previamente assimiladas.

Obviamente que existem diferenças notórias entre a Contabilidade ensinada em pleno século XVIII e a actual, não seria de esperar outra coisa. Contudo, muitas das regras, recomendações apresentadas e dos cuidados a ter ainda hoje fazem sentido e são válidas, não obstante o facto de se inserirem em uma perspectiva de maior complexidade, serem realizadas através de outros métodos, etc.

Para finalizar umas últimas palavras para os interessados em história da Contabilidade Portuguesa, em geral, e da Aula do Comércio, em particular. Assim, além do manuscrito aqui apresentado, existem outras obras, datadas do século XVIII, que permitem avaliar o ensino da Contabilidade na Aula do Comércio e cujo estudo seria deveras admirável e interessante: Pratica do commercio ou lições da aula do commercio que principiou em 1-9-1759 dictadas pelo Lente João Henrique de Souza, de João Henrique de Souza; Notícia Geral do Comércio; e o Diccionario do Commercio, ambas de Alberto Jacqueri de Sales, segundo Lente da Aula do Comércio. 


\section{REFERÊNCIAS}

BELKAOUI, Ahmed Ruahi. Accounting Theory, $3^{a}$ edição. London: The Dryden Press, 1994.

BOXER, Charles A. O Império Colonial Português. Lisboa: Edições 70, 1977.

CAIADO, António. Historiadores de Contabilidade, precisam-se!. Boletim do Centro de Estudos de História da Contabilidade, Lisboa, n. 4, p. 1, abr. 1999.

CAIADO, António Pires. O ensino da Contabilidade na Aula do Comércio (1759-1844). In: IX JORNADAS DE CONTABILIDADE E FISCALIDADE: A CONTABILIDADE - DESAFIOS AO VIRAR DO SÉCULO, 2000, Lisboa. Anais... Lisboa: [s.n.], 2000. 1 CD-ROM.

CARNEGIE, Garry. O passado da Contabilidade em Portugal. Revista Contabilidade e Gestão, Lisboa, n. 1, p. 15-17, jul. 2005.

CARVALHO, Rómulo. História do ensino em Portugal: desde a fundação da nacionalidade até ao fim do regime de Salazar-Caetano, 2. ${ }^{a}$ edição. Lisboa: Fundação Calouste Gulbenkian, 1996.

CERVO, Amado Luiz; BERVIAN, Pedro Alcino. Metodologia Científica. 5.ed. São Paulo: Makron Books, 2002.

ESTEVENS, Matilde. Das origens do comércio em Portugal à obrigatoriedade de utilização do método das partidas dobradas. In: VIII CONGRESSO DE CONTABILIDADE E AUDITORIA: A CONTABILIDADE NA VIRAGEM DO MILÉNIO, 2000, Aveiro. Anais... Aveiro: [s.n.], 2000. 1 CD-ROM.

GOMES, Delfina. Um livro português do século XVIII. Revista de Contabilidade e Comércio, Lisboa, V. LVI, n. 223, p. 547-555, nov. 1999a.

GOMES, Delfina. Os livros de receitas e despesas da Câmara Municipal de Braga. Lisboa: Centro de Estudo de História da Contabilidade, 1999b.

GOMES, Delfina. A evolução dos registos contabilísticos e a aplicação da partida dobrada em Portugal. 2000. 328 f. Dissertação (Mestrado em Contabilidade e Auditoria) Escola de Economia e Gestão da Universidade do Minho, Braga, 2000.

GONÇALVES, Miguel. Análise estatutária das normas atinentes à regulação da Aula do Comércio de Lisboa (1759): uma reflexão adicional. Jornal de Contabilidade, Lisboa, $\mathrm{n}$. 399, p. 164-167, jun. 2010. 
GONÇALVES, Miguel; MARQUES, Maria da Conceição. Da necessidade da criação do ensino de Contabilidade para o ofício de Guarda-Livros no Portugal de setecentos. Jornal de Contabilidade, Lisboa, n. 404 , p. 328-334, nov. 2010.

GUIMARÃES, Joaquim. Primórdios do desenvolvimento das ciências empresariais e da Contabilidade em Portugal. Boletim do Centro de Estudos de História da Contabilidade, Lisboa, n. 7, p. 3, jan. 2000.

GUIMARÃES, Joaquim. História (breve) da regulamentação da profissão de contabilista. Revista TOC, Lisboa, n. 123, p. 31-45, jun. 2010.

KOURGANOFF, Wladimir. A face oculta da universidade. Trad. Cláudia Schilling e Fátima Murad. São Paulo: Editora UNESP, 1990.

MARQUES, Maria da Conceição. A evolução do pensamento contabilístico nos séculos XV a XIX. Jornal do Técnico de Contas e da Empresa, Lisboa, n. 414, p. 69-72, mar. 2000, e n. 415 , p. 107-111, abr 2000.

MARTINS, Manuel de Everard. Para a história da Contabilidade pública em Portugal. Separata de: Revista de Contabilidade e Comércio, Lisboa, n. 80, p. 427-457, [?] 1952.

MARTINS, Manuel de Everard. AAula do Comércio (1759). Boletim da Sociedade Portuguesa de Contabilidade, Lisboa, n. 21 e 22, p. 71-88, [?] 1960.

OLIVEIRA, Isabel. A Contabilidade da Real Companhia Velha no período Pombalino. Jornal de Contabilidade, Lisboa, n. 392, p. 361-374, nov. 2009.

RAUPP, Fabiano; BEUREN, Ilse. Metodologia da pesquisa aplicável às Ciências Sociais. In: LONGARAY, A. A.; RAUPP, F. M.; BEUREN, I. M.; SOUSA, M. A. B.; COLAUTO, R. D.; PORTON, R. A. B. (Org.). Como Elaborar Trabalhos Monográficos em Contabilidade: Teoria e Prática, 3. ${ }^{a}$ ed. São Paulo: Editora Atlas, 2006, p. 76-97.

RODRIGUES, Lúcia; GOMES, Delfina; CRAIG, Russel. Aula do Comércio: Primeiro estabelecimento de ensino técnico profissional oficialmente criado no Mundo?. Revista TOC, Lisboa, n. 34, p. 46-54, jan. 2003a.

RODRIGUES, Lúcia; GOMES, Delfina; CRAIG, Russel. Corporatism, liberalism and accounting profession in Portugal since 1755. Accounting Historians Journal, Oxford, Vol. 30, n. 1, p. 95-111, June 2003b. 
RODRIGUES, Lúcia; GOMES, Delfina; CRAIG, Russel. State intervention in commercial education: the case of the Portuguese School of Commerce - 1759. Accounting History, [s. I.], Vol. 12, n. 1, p. 55-85, Feb. 2007.

RODRIGUES, Lúcia; GOMES, Delfina; CRAIG, Russel. A intervenção do Estado no ensino comercial: o caso da Aula do Comércio, 1759. Revista TOC, Lisboa, n. 118, p. 39-48, jan. 2010, e n. 119, p. 39-44, fev. 2010.

RODRIGUES, Lúcia; CRAIG, Russel. English Mercantilist Influences on the foundation of the portugueses School of Commerce in 1759. Atlantic Economic Journal, Atlanta. Vol. 32, n. 4, p. 329-345, Dec. 2004.

RODRIGUES, Lúcia; CRAIG, Russel. Teachers as servants of state ideology: Sousa and Sales, Portuguese School of Commerce, 1759-1784. Critical Perspectives on Accounting, [s. I.], Vol. 20, n. 3, p. 379-398, Apr. 2009.

RODRIGUES, Lúcia; GOMES, Delfina. Evolução da profissão dos Técnicos de Contas em Portugal: Do Marquês de Pombal até aos nossos dias. In: II JORNADAS DE HISTÓRIA DA CONTABILIDADE, 2002, Lisboa. Anais... Lisboa: [s.n.], 2002. 1 Pen-drive.

SILVA, F. Gonçalves da. Bosquejo duma sucinta histórica da Contabilidade em Portugal. Revista de Contabilidade e Comércio, Lisboa, n. 205, p. 503-514, out. 1984.

SOUSA, José de. Reformismo social e projecto educativo: António Sérgio, defensor do «ensino técnico-profissional». In: II JORNADAS DE CONTABILIDADE, 1984, Aveiro. Anais... Aveiro: ISCAA, 1985. p. 540-557.

SOUZA, João Henrique. Arte da Escritura Dobrada que Dictou na Aula do Commercio João Henrique de Souza e copeada para Instrucçaõ de Joze Feliz Venancio Cout. ${ }^{\circ}$ no Anno de 1765. [Lisboa]: [s.n.], 1765.

1 O seu título completo é Arte da Escritura Dobrada que Dictou na Aula do Commercio João Henrique de Souza e copeada para Instrucçaõ de Joze Feliz Venancio Cout. ${ }^{\circ}$ no Anno de 1765. Devido a este extenso título, usaremos durante este trabalho o título abreviado já referido: Arte de Escritura dobrada, para Instrucção de Joze Feliz Venancio.

2 Embora o curso começasse por ter a duração de três anos, os primeiros cursos excederam em alguns meses o triénio que lhes competia (RODRIGUES; GOMES; CRAIG, 2003a).

3 A Junta do Comércio foi criada por Real Decreto de 30 de Setembro de 1755, tendo os seus estatutos sido promulgados em 16 de Dezembro de 1756. Sobressaem, de entre as funções que Ihe foram atribuídas, organizar e disciplinar o comércio, e estimular, criar e administrar novas fábricas.

4 SANTANA, Francisco. A Aula do Comércio de Lisboa (1759-1844). Revista Municipal de Lisboa, Lisboa, n.s 15, 16 e 18 a 23 , [?], 1989. 
5 O júri destas provas era composto por três elementos: o Presidente, que era o Desembargador Deputado Inspector, e dois vogais, que eram Deputados da Junta do Comércio.

6 Por "Decúrias" entenda-se a prática estabelecida nos primórdios da Aula do Comércio - e que provavelmente terá sido seguida durante toda a existência desta instituição - que consistia na celebração de aulas, chamemos assim, por parte dos melhores alunos, com o apoio do Lente, onde eram repetidas, aos restantes alunos, as matérias já leccionadas pelo Lente (RODRIGUES, GOMES E CRAIG, 2003a).

7 Os períodos lectivos estendiam-se de Outubro a Junho, realizando-se os exames em Julho.

8 Como exemplo temos os escritórios das Casas de Negócio, assinantes das Alfândegas, escrivães das Naus da Real Armada e navios mercantes, diversos empregos das Companhias Gerais, Feitorias, Medidores e Lotadores de Navios (RODRIGUES; GOMES, 2002).

9 Não deverá ser esquecido que o objectivo da Aula do Comércio era reverter a precária situação existente quando D. José, e consequentemente o Marquês de Pombal, chegaram ao poder: o conhecimento existente por parte dos cidadãos portugueses sobre matérias contabilísticas e comerciais era nulo ou quase inexistente.

10 Embora no ano de 1765, constante do título do manuscrito, o mesmo Lente já não se encontrasse em funções na Aula do Comércio.

11 A cópia deste manuscrito a que tivemos acesso pertence ao acervo da Biblioteca Nacional de Portugal, com a cota COD. 13099, sendo constituído por 452 páginas, todas numeradas, embora algumas delas estejam em branco (como, por exemplo, se pode constatar nas páginas 157 a 160) e está encadernada em pele.

12 A ordem dos livros utilizados, quer sejam os gerais ou os auxiliares, é baseada nas letras do abecedário, isto é, o primeiro Borrão, o primeiro Diário, o primeiro Razão, devem ser assinalados com a letra A. Quando estes terminarem e se iniciarem novos livros, estes serão assinalados com a letra $B$, e assim sucessivamente.

13 "Tirar o Balanço do Livro de Razão, é assentar em um papel (ou Caderno, se as contas são muitas), de uma parte os restos das contas devedoras, e da outra os restos das contas credoras" (SOUZA, 1765, p. 75).

14 Para ser obtida uma maior fiabilidade são indicados novos livros passíveis de serem utilizados, como por exemplo o Livro de Entrada de Fazendas, Livro de Vendas Fiadas, Livros de Gastos, Livros de Vendas que funcionavam como um Borrador mais específico, bem como novas regras de manuseamento (SOUZA, 1765).

15 A criação desta instituição escolar ficou de fora da luta entre o Conde de Oeiras e a Companhia de Jesus, e é, cronologicamente, a primeira providência tomada pelo ministro de D. José para ocorrer às necessidades do ensino de então (CARVALHO, 1996). 